\title{
Clinical and Epidemiological Differences between Women and Men with HIV Infection in Mexico
}

Mata-Marín José Antonio", Chaparro-Sánchez Alberto ${ }^{1 *}$, Hernández-López Juan Carlos², Huerta-García Gloria ${ }^{3}$, Domínguez-Hermosillo Juan Carlos ${ }^{1}$ and Cruz-Domínguez Pilar $^{2}$

${ }^{1}$ Infectious Diseases Department, Hospital de Infectología, "La Raza" National Medical Center, IMSS, Mexico

2Internal Medicine Department, Hospital de Especialidades, "La Raza" National Medical Center, IMSS, Mexico

${ }^{3} P$ ediatric Infectious Diseases Department, Hospital de Pediatría, "Siglo XXI" National Medical Center, IMSS, Mexico

\begin{abstract}
Objective: To evaluate the differences in gender for epidemiological, immunological, and virological outcomes at baseline, and response after 24 weeks of antiretroviral therapy in patients treated at the Hospital de Infectología "La Raza" National Medical Center.

Methods: We reviewed the medical records from March to August 2014 of outpatients who started treatment in our clinic; 65 women and 138 men in a cross-sectional study. Descriptive results are summarized using the median and $25^{\text {th }}-75^{\text {th }}$ interquartile range (IQR). Baseline differences were tested using Fisher's exact test and the Chi-squared test. Analyses of continuous variables were performed using the Mann-Whitney $U$ test.
\end{abstract}

Results: Similar proportions of women and men were found in the following factors: living in metropolitan area, age $<40$ years, economic household income source, baseline CD4 $+\leq 200$ cells/ $\mu \mathrm{L}, \mathrm{CD} 4+\geq 200 \mathrm{cells} / \mu \mathrm{L}$ at week 24 HIV-1 RNA $\leq 50$ copies $/ \mathrm{mL}$ at week 24 , and opportunistic infections. Women are more usually married than men $(75 \%$ vs. $10 \%, p<0.001)$; men with a higher academic degree (34\% vs. $9 \%, p<0.001)$; men with an onset of sexual activity $<20$ years $(85 \%$ vs. $79 \%, p=0.26)$; women with $\leq 4$ sexual partners $(92.3 \%$ vs. $26.3 \%, p<0.001)$; women with children $(92 \%$ vs. $20 \%$, $p<0.001)$; men with some addiction ( $29 \%$ vs. $10 \%, p=0.04)$; women with baseline HIV-1 RNA viral load $>100,000$ copies $/ \mathrm{mL}$ ( $37 \%$ vs. $54 \%, p=0.020)$; and women with virological treatment failure $(10.8 \%$ vs. $2.2 \%, p=0.008)$.

Conclusion: Compared with men, mostly women showed adverse epidemiological and clinical conditions that made women more vulnerable to transmission through heterosexual activity, and more frequently present virological failure.

Keywords: HIV; CD4 cell count; Viral load; Gender differences; Women; Outcome, Women with HIV

\section{Introduction}

In 2014, the Joint United Nations Programme on HIV/AIDS (UNAIDS) estimated a global prevalence of 35.3 million people with human immunodeficiency virus (HIV) infection. The prevalence of women with HIV is increasing: data from the USA estimate an increase from $7 \%$ in 1985 to $27 \%$ in 2007 [1]. The latest estimates indicate that 147,137 people are living with HIV in Mexico [2]. In Mexico, the prevalence in women is estimated to be $18 \%$, with a female:male prevalence ratio of approximately 1:4. The predominant mode of male transmission is via men who have sex with men, but for women the heterosexual transmission rate is around 90\% [3]. Recent studies estimate an increase in the prevalence of women with HIV infection in rural areas in Mexico [4,5].

Access to diagnosis, tests, and treatment has been unequal between genders, and factors associated with this are the lack of transport [6], childcare, lack of time [7], and economic factors [8], all making women more vulnerable to HIV infection, care approach, loss of followup and virologic failure. Studies in other countries have shown that men initiate treatment at later stages of the disease compared with women [9-11]. The impact of an early initiation of antiretroviral therapy (ART) in reducing mortality has been documented [12-14]. In the UK, it was found that women with HIV infection now have an increase in life expectancy compared with men [15]. A similar situation was found in Latin America, in a retrospective study in Buenos Aires, where men who initiated ART were in more advanced stages of the disease than women: $59.8 \%$ vs. $40.2 \%$ [16]. Other reports have suggested a more vulnerable situation for infection of women insome countries, such as having a lower educational level than men [17-19]. Moreover, the sexual behavior of men confers a risk factor for women, whereas the main risk factor for HIV infection in women is to be married to an HIV-positive partner [20]. The widespread use of ART worldwide has decreased the overall mortality considerably $[21,22]$, even in populations with low resources. Adherence to treatment and an undetectable HIV RNA viral load (VL) are important predictors of mortality but there are gender differences that make these endpoints difficult to achieve in vulnerable populations [23]. Kumarasamy et al. evaluated the response to ART according to gender and found a better immune response in women than in men, who had a $20 \%$ increased risk of death at 24 and 36 months of treatment [24].

We have no scientific information on the clinical and epidemiological characteristics and differences between men and women infected with $\mathrm{HIV}$ and receiving ART in Mexico. The aim of this study was to evaluate

*Corresponding author: Dr. Alberto Chaparro Sánchez, Instituto Mexicano del Seguro Social, Hospital de Infectología, Centro Médico Nacional "La Raza", Seris y Jacarandas s/n, colonia la Raza, Del. Azcapotzalco, México, DF, CP. 02990, Tel: 57825900; ext 23924; E-mail: a_chaparro@hotmail.com

Received December 03, 2015; Accepted February 24, 2016; Published March 04, 2016

Citation: Antonio MMJ, Alberto CS, Carlos HLJ, Gloria HG, Carlos DHJ, et al (2016) Clinical and Epidemiological Differences between Women and Men with HIV Infection in Mexico. J AIDS Clin Res 7: 551. doi:10.4172/2155-6113.1000551

Copyright: (c) 2016 Antonio MMJ, et al. This is an open-access article distributed under the terms of the Creative Commons Attribution License, which permits unrestricted use, distribution, and reproduction in any medium, provided the original author and source are credited. 
the differences in epidemiological, immunological, and virological outcome at baseline and response with respect to gender after 24 weeks of ART in patients treated at the Hospital de Infectología "La Raza" National Medical Center, a tertiary-level infectious diseases care hospital in Mexico City.

\section{Methods}

\section{Design}

We conducted a cross-sectional study at our institution from March to August 2014. A non-probabilistic sample was done with the files analized.

\section{Patients}

Eligible patients needed to be $>16$ years old of age with an HIV1 infection confirmed by enzyme-linked immunosorbent assay and western blotting, and being treated with ART in our HIV clinic. Patients were invited to participate by completing a questionnaire. All participants were outpatients who started treatment in our clinic and whose medical records were used to collect information about sociodemographic characteristics, CD4+ cell count, HIV-1 RNA VL, blood chemistry, liver function tests, and blood cell counts at the first visit. Our hospital institutional review board and ethics committee reviewed and approved this study (reference number R-2014-3502139).

\section{Measurements and procedures}

Data were collected from medical records regarding demographic factors for each gender: age, educational level, area of residence, household income source, number of children, heterosexual or homosexual activities, age at the onset of sexual activity, numbers of sexual partners, any illicit drug use, history of opportunistic infections, hepatitis serology, baseline CD4+ cell count, baseline CD4+ cell count of $<200$ cell/ $\mu \mathrm{L}$, baseline HIV-1 RNA VL, baseline HIV-1 RNA VL of $>100,000$ copies/mL, and CD4+ cell count and HIV-1 RNA VL at week 24 of treatment. Virological failure was defined as an HIV-1 RNA VL of $>200$ copies $/ \mathrm{mL}$ in two separate consecutive samples once HIV was undetectable, or an HIV-1 RNA VL of $>200$ copies/mL at week 24 after the initiation of ART.

\section{Statistical analysis}

Analyses were performed using IBM SPSS software (version 20.0; IBM Corp, Armonk, NY, USA). The Kolmogorov-Smirnov test was used to determine the normality of sample distributions. Descriptive results are summarized using the median and $25^{\text {th }}-75^{\text {th }}$ interquartile range (IQR). Baseline differences regarding categorical variables were tested using Fisher's exact test and the Chi-squared test. Analyses of continuous variables were performed using the Mann-Whitney U test.

\section{Results}

We included 203 patients, 65 of whom were women. The median age of the women was 35 years (IQR27-42), and 13 (20\%) were $>50$ years old. The median age of the men was 33 (IQR 27-43) years old, and $18(13 \%)$ were $>50$ years old. Most patients started treatment with tenofovir/emtricitabine (TDF/FTC) plus efavirenz (EFV); abacavir/ lamivudine (ABC/3TC) plus EFV; TDF/FTC plus atazanavir/ritonavir $(\mathrm{ATV} / \mathrm{r})$; or $\mathrm{ABC} / 3 \mathrm{TC}$ plus $\mathrm{ATV} / \mathrm{r}$.

More women than men were living in metropolitan areas $(64 \% \mathrm{vs.}$ $52 \%)$. Some differences were found in the marital status where more of women are married compared with men $(75 \%$ vs. $10 \%$; $\mathrm{p}<0.001)$.
Men had a higher educational level than women ( $34 \%$ vs. $9 \%$; $\mathrm{p}<0.001)$. More women had $\leq 4$ sexual partners than men ( $92 \%$ vs. $26 \%$; $<<0.001)$. More women had children compared with men ( $92 \%$ vs. $19 \%$; $\mathrm{p}<0.001)$ and more men had some drug addictions compared with women $(29 \%$ vs. $10 \%$; $\mathrm{p}=0.04)$.

A baseline CD4+ cell count of $\leq 200$ cells/ $\mu \mathrm{L}$ was found in $53 \%$ of women compared with $50 \%$ of men. The median baseline HIV1 RNA VL was 44,000 copies/mL (IQR 25078-233,722) in women versus126,765 copies/mL (IQR 46,372-343,215) in men, and women had fewer opportunistic infections than men (20\% vs. $30 \%)$.

Other differences were found such as a lower median CD4+ cell count at week 24 of treatment in women ( 289 vs. $358 ; \mathrm{p}=0.061$ ). Women had a lower rate of reaching an HIV-1 RNA VL of $<50$ copies $/ \mathrm{mL}$ at 24 weeks ( $80 \%$ vs. $90 \%$; $\mathrm{p}=0.028$ ), and a higher proportion of women than men had virological failure ( $10 \%$ vs. $2 \% ; \mathrm{p}=0.008)$ (Tables 1 and 2$)$.

\section{Discussion}

Significant differences were found between women and men with HIV infection in terms of epidemiological, clinical, and virological

\begin{tabular}{|l|c|c|c|}
\hline \multicolumn{1}{|c|}{ Characteristics } & $\begin{array}{c}\text { Women } \\
(\mathbf{n = 6 5 )}\end{array}$ & $\begin{array}{c}\text { Men } \\
(\mathbf{n}=138)\end{array}$ & p value \\
\hline Age (y), median (IQR) & $35(27-42)$ & $33(27-43)$ & 0.562 \\
\hline Age >50 years old, $\mathrm{n}(\%)$ & $13(20)$ & $18(13)$ & 0.199 \\
\hline Living in metropolitan area, $\mathrm{n}(\%)$ & $41(63)$ & $71(52)$ & 0.120 \\
\hline University study, $\mathrm{n}(\%)$ & $6(9)$ & $48(34)$ & $<0.001$ \\
\hline Married status, $\mathrm{n}(\%)$ & $49(75)$ & $14(10)$ & $<0.001$ \\
\hline Children, $\mathrm{n}(\%)$ & $60(92)$ & $27(20)$ & $<0.001$ \\
\hline Current drug user, $\mathrm{n}(\%)$ & $7(10)$ & $40(29)$ & 0.004 \\
\hline $\begin{array}{l}\text { Age in y at the onset of sexual activity, median } \\
\text { (IQR) }\end{array}$ & $18(16-19)$ & $18(16-19)$ & 0.690 \\
\hline Onset of sexual activity $\leq 20$ years old, $\mathrm{n}(\%)$ & $51(79)$ & $117(85)$ & 0.266 \\
\hline Number of sexual partners, median (IQR) & $2(1-3)$ & $8(4-20)$ & $<0.001$ \\
\hline Sexual partners $\leq 4, \mathrm{n}$ (\%) & $60(92)$ & $36(26)$ & $<0.001$ \\
\hline Sexual transmission, $\mathrm{n}(\%)$ & $63(97 \%)$ & $137(99 \%)$ & 0.19 \\
\hline Other transmission, $\mathrm{n}(\%)$ & $2(3 \%)$ & $1(1 \%)$ & 0.19 \\
\hline Opportunistic infections at the beginning, $\mathrm{n}(\%)$ & $13(20)$ & $41(30)$ & 0.230 \\
\hline
\end{tabular}

Key: y, years; IQR, interquartile rate. Differences were considered statistically significant at $p \leq 0.05$.

Table 1: Epidemiological characteristics.

\begin{tabular}{|c|c|c|c|}
\hline Baseline characteristics & Women $(n=65)$ & Men $(n=138)$ & p value \\
\hline CD4+ cells/ $\mu \mathrm{L}$, median (IQR) & $175(130-221)$ & $203(148-244)$ & 0.605 \\
\hline CD4+<200 cells/ $\mu \mathrm{L}, \mathrm{n}(\%)$ & $35(53)$ & $69(50)$ & 0.535 \\
\hline $\begin{array}{l}\text { HIV-1 RNA VL, copies/mL, median } \\
\text { (IQR) }\end{array}$ & $\begin{array}{c}44,000 \\
(25078-233,722)\end{array}$ & $\begin{array}{c}126,765 \\
(46,372-343,215)\end{array}$ & 0.001 \\
\hline $\begin{array}{l}\text { HIV-1 RNA VL >100,000 copies/ } \\
\text { mL, } n(\%)\end{array}$ & $24(37)$ & $75(54)$ & 0.020 \\
\hline \multicolumn{4}{|c|}{ Variables at week 24} \\
\hline CD4+ cells/ $\mu \mathrm{L}$, median (IQR) & $289(192-437)$ & $358(216-519)$ & 0.061 \\
\hline $\begin{array}{l}\text { HIV-1 RNA VL copies/mL, median } \\
\text { (IQR) }\end{array}$ & $40(19-205)$ & $78(19-402)$ & 0.33 \\
\hline HIV-1 RNA VL <50 copies/mL, n (\%) & $52(80)$ & $124(90)$ & 0.028 \\
\hline $\begin{array}{l}\text { Withdrawal because of adverse } \\
\text { events, } \mathrm{n}(\%)\end{array}$ & $4(6)$ & $3(2)$ & 0.147 \\
\hline Virological failure, n (\%) & $7(10)$ & $3(2)$ & 0.008 \\
\hline Interruption for other causes, n (\%) & $2(3)$ & $8(6)$ & 0.403 \\
\hline
\end{tabular}

Key: VL, viral load; IQR, interquartile rate. Differences were considered statistically significant at $\mathrm{p} \leq 0.05$.

Table 2: Virological and immunological characteristics at baseline and after 24 weeks of ART. 
characteristics. Compared with men, women were more usually married, had a lower educational level, fewer sexual partners, and more usually had children. In addition, women had a baseline level of CD4+ cell count similar to men but with a lower baseline HIV-1 RNA viral load level. Finally, women were more likely than men to show virological failure after 24 weeks of ART.

These characteristics of men and women with HIV infections are similar to those observed in other studies worldwide, namely women are more vulnerable and have lower socioeconomic profiles than men [1]. The psychosocial burden for women infected with HIV/AIDS is greater than their physical burden, because it will hamper their survival and can cause emotional and mental health problems and poor medication adherence [25]. A study at the John Hopkins HIV clinic reported that $54 \%$ of women with HIV/AIDS were also diagnosed with psychopathologies: $20 \%$ suffered from severe depression; $18 \%$ had adjustment disorders; and $74 \%$ had a substance abuse disorder [26]. Mental and emotional disorders, and especially depression in people with HIV/AIDS, might affect medication adherence leading to virological failure [27].

Similar to our study, in a multinational clinical trial, women had a lower HIV-1 RNA viral load than men; in contrast, the same study showed that women presented with a higher CD4+ cell count than men [25]. However, in our study, we did not find this difference.

Women in our study were more likely than men to have children; in other studies, the primary caregiver of children and the number of children have been associated with poor virological outcome $[28,29]$.

One study carried out in Colombia, a country with sociodemographic similarities with Mexico, found that $43 \%$ of the women showed low adherence to treatment and $80 \%$ were classified as having a low social status [30]. Most of the variables in the social position survey had a significant effect on low adherence, including low socioeconomic status (odds ratio, $\mathrm{OR}=2.26$; 95\% confidence interval, $\mathrm{CI}=1.2-4.04$ ) and an educational level of high school or less $(\mathrm{OR}=2.850 ; 95 \% \mathrm{CI}=1.625$ 5.000). However, unlike our study, they found that sociodemographic variables and clinical variables that did not have a significant effect on adherence included being solely responsible for the family income, having children, and living with children with or without a partner.

Our results are similar to those of some clinical trials that found a higher frequency of virological failure in women [29-31]. Univariate analysis of factors associated with nonadherence, antiretroviral discontinuation, and poor virological response were being the primary caregiver for children, being unemployed, having a low educational level, and having transportation difficulties. The major sex-based differences in responses might have been caused by higher discontinuation rates in women in those studies. However, a study in Spain showed a similar response in both sexes [32].

The limitations of the current study did not allow us to compare epidemiological and clinical characteristics in certain groups, such as infected heterosexual couples, or to compare variables and infer risk factors for vulnerability to infection. Because of the small sample size, we were not able to compare between ART regimens or between some factors such as women living in rural areas compared with those living in metropolitan areas. In addition, we could not evaluate the impact of unemployment, because we retrieved our data from clinical charts. In spite of these study limitations, we obtained relevant information about differences between women and men in our Mexican population. A prospective multicenter study should be developed to evaluate these data further and to obtain more epidemiological and clinical information on vulnerable characteristics among women with HIV infection.

In conclusion, these Mexican women showed differences in epidemiological and clinical characteristics that could have had an impact on their virological and immunological responses to ART. Improving women's adherence to HIV/AIDS treatment in Mexico would require eliminating barriers to the national health care system and comprehensive health care services, and implementing programs that take into account women's role as maternal caregivers. Our findings underscore the need to integrate social determinants of health associated with gender inequality and social position when analyzing treatment response.

\section{Acknowledgments}

We would like to thank all the physicians that were involved with the follow up of the patients and to all the patient's families because of their trust and patience.

\section{References}

1. UNAIDS (2013) Global report: UNAIDS report on the global AIDS epidemic 2010. World Health Organization, Geneva.

2. CENSIDA/Secretaría de Salud (2012) EI VIH/SIDA en México.

3. Magis-Rodríguez C, De Luca M, Bravo-García E, Rivera-Reyes P, OrtizMondragón R, et al. (2010) [The AIDS epidemics in Mexico up to 2008]. Gac Med Mex 146: 45-49.

4. Brouwer KC, Strathdee SA, Magis-Rodríguez C, Bravo-García E, Gayet C, et al. (2006) Estimated numbers of men and women infected with HIVIAIDS in Tijuana, Mexico. J Urban Health 83: 299-307.

5. Centers for Disease Control and Prevention (CDC) (2011) Vital signs: HIV prevention through care and treatment--United States. MMWR Morb Mortal Wkly Rep 60: 1618-1623.

6. Stein MD, Crystal S, Cunningham WE, Ananthanarayanan A, Andersen $\mathrm{RM}$, et al. (2000) Delays in seeking HIV care due to competing caregiver responsibilities. Am J Public Health 90: 1138-1140.

7. Cunningham WE, Andersen RM, Katz MH, Stein MD, Turner BJ, et al. (1999) The impact of competing subsistence needs and barriers on access to medical care for persons with human immunodeficiency virus receiving care in the United States. Med Care 37: 1270-1281.

8. Oliva J, Galindo S, Vives N, Arrillaga A, Izquierdo A, et al. (2010) [Delayed diagnosis of HIV infection in Spain]. Enferm Infecc Microbiol Clin 28: 583-589.

9. Centers for Disease Control and Prevention (CDC) (2013) Differences between HIV-infected men and women in antiretroviral therapy outcomes-six African countries, 2004-2012. MMWR Morb Mortal Wkly Rep 62: 945-952.

10. Sendagire I, Cobelens F, Kambugu A, Konde-Lule J, van der Loeff MS (2012) Frequency and predictors for late start of antiretroviral therapy in primary care clinics, Kampala, Uganda. J Acquir Immune Defic Syndr 61: e33-39.

11. Alvarez-Uria G (2013) Factors associated with delayed entry into HIV medical care after HIV diagnosis in a resource-limited setting: data from a cohort study in India. Peer J 1:e90.

12. Egger M, Hirschel B, Francioli P, Sudre P, Wirz M, et al. (1997) Impact of new antiretroviral combination therapies in HIV infected patients in Switzerland: prospective multicentre study. Swiss HIV Cohort Study. BMJ 315: 1194-1199.

13. Antiretroviral Therapy Cohort Collaboration, Zwahlen M, Harris R, May M, Hogg $\mathrm{R}$, et al. (2009) Mortality of HIV-infected patients starting potent antiretroviral therapy: comparison with the general population in eight industrialized countries. Int J Epidemiol 38: 1624-1633.

14. Losina E, Schackman BR, Sadownik SN, Gebo KA, Walensky RP, et al (2009) Racial and sex disparities in life expectancy losses among HIV-infected persons in the United States: impact of risk behavior, late initiation, and early discontinuation of antiretroviral therapy. Clin Infect Dis 49: 1570-1578.

15. May M, Gompels M, Delpech V, Porter K, Post F, et al. (2011) Impact of late diagnosis and treatment on life expectancy in people with HIV-1: UK Collaborative HIV Cohort (UK CHIC) Study. BMJ 343: d6016.

16. Warley E, Fernández Galimberti G, Vieni MI, Tavella S, Salas M, et al. (2012) 
Citation: Antonio MMJ, Alberto CS, Carlos HLJ, Gloria HG, Carlos DHJ, et al. (2016) Clinical and Epidemiological Differences between Women and Men with HIV Infection in Mexico. J AIDS Clin Res 7: 551. doi:10.4172/2155-6113.1000551

Page 4 of 4

Factors associated to late clinical stage at the initiation of antiretroviral therapy. Medicina (B Aires) 72: 367-370.

17. Giménez-García C, Ballester-Arnal R, Gil-Llario MD, Cárdenas-López G, Duran-Baca X (2013) Culture as an influence on the perceived risk of HIV infection: a differential analysis comparing young people from Mexico and Spain. J Community Health 38: 434-442.

18. Zambrana RE, Cornelius LJ, Boykin SS, Lopez DS (2004) Latinas and HIV/ AIDS risk factors: implications for harm reduction strategies. Am J Public Health 94: 1152-1158.

19. Hirsch JS, Meneses S, Thompson B, Negroni M, Pelcastre B, et al. (2007) The inevitability of infidelity: sexual reputation, social geographies, and marital HIV risk in rural Mexico. Am J Public Health 97: 986-996.

20. Jiang S, Li W, Lu L (2013) Controlling HIV sexual transmission: a major challenge for China's new leadership. Cell Biosci 3: 17.

21. Jensen-Fangel S, Pedersen L, Pedersen C, Larsen CS, Tauris P, et al. (2004) Low mortality in HIV-infected patients starting highly active antiretroviral therapy, a comparison with the general population. AIDS 18: 89-97.

22. Chêne G, Sterne JA, May M, Costagliola D, Ledergerber B, et al. (2003) Prognostic importance of initial response in HIV-1 infected patients starting potent antiretroviral therapy, analysis of prospective studies. Lancet 362: 679686 .

23. Cornell M, Myer L, Kaplan R, Bekker LG, Wood R (2009) The impact of gender and income on survival and retention in a South African antiretroviral therapy programme. Trop Med Int Health 14: 722-731.

24. Kumarasamy N, Venkatesh KK, Cecelia AJ, Devaleenol B, Saghayam S, et al. (2008) Gender-based differences in treatment and outcome among HIV patients in South India. J Womens Health (Larchmt) 17: 1471-1475.
25. Mehat AK, Gupta S (2008) The impact of HIVIAIDS on women care givers in situations of poverty: policy issues. Am J Psychol 18: 267-279.

26. Angelino AF (2008) Impact of psychiatric disorders on the HIV epidemic. Top HIV Med 16: 99-103.

27. Préau M, Marcellin F, Carrieri MP, Lert F, Obadia Y, et al. (2007) Health-related quality of life in French people living with HIV in 2003: results from the national ANRS-EN12-VESPA Study. AIDS 21 Suppl 1: S19-27.

28. Firnhaber C, Smeaton LM, Grinsztejn B, Lalloo U, Faesen S, et al. (2015) Differences in antiretroviral safety and efficacy by sex in a multinational randomized clinical trial. HIV Clin Trials 16: 89-99.

29. Bailey H, Townsend CL, Cortina-Borja M, Thorne C; European Collaborative Study in Euro Coord (2013) Improvements in virological control among women conceiving on combination antiretroviral therapy in Western Europe. AIDS 27 2312-2315.

30. Arrivillaga M, Ross M, Useche B, Alzate ML, Correa D (2009) Social position gender role, and treatment adherence among Colombian women living with HIVIAIDS: social determinants of health approach. Rev Panam Salud Publica 26: $502-510$.

31. Squires K, Feinberg J, Bridge DA, Currier J, Ryan R, et al. (2013) Insights on GRACE (Gender, Race, And Clinical Experience) from the patient's perspective: GRACE participant survey. AIDS Patient Care STDS 27: 352-362.

32. Pérez-Molina JA, Mora Rillo M, Suárez-Lozano I, Casado-Osorio JL, Teira Cobo $R$ et al. (2012) Response to combined antiretroviral therapy according to gender and origin in a cohort of naïve HIV-infected patients: GESIDA-5808 study. HIV Clin Trials 13: 131-141. 